\title{
Assessment of Factors Contributing to Indoor Air Pollutants Exposure and Prevalence of Respiratory Health Problems in Seka Town
}

\author{
Mr Bekele Terefe Tucho Mr Samuel Fikadu Mr Chala Kenenisa Edae \\ Jimma University, Jimma, Ethiopia
}

\begin{abstract}
Objective: The main objective this study is to assess factors contributing to combustion and non-combustion related indoor air pollutants exposure and related prevalence of respiratory health problem among women and young children in Seka town.

Methods: The study used a household-based cross-sectional study design from May 1-30, 2017. A systematic random sampling technique was used to select the 341 households included in the survey. The survey instrument was specific structured questionnaire that was adapted from WHO guidelines for survey of household fuel use indoor spray and acute respiratory infections. Concentration of total suspended particles(TSP) was measured in small subset of 34(10\%) sampled households during the cooking and non-cooking hours using SKC 52 model air sampling pump. The survey data was analyzed by using a software package SPSS version 20.Logistic regression analysis was used to determine the association of household fuel using characteristics to ARI and descriptive statistics such as frequency distributions and measure of central tendencies were used to describe concentrations of total suspended particulates.
\end{abstract}

Results: The finding from the survey analysis shows that $332(97.4 \%)$ of mothers were exposed to indoor air pollution during cooking. Majority of the respondents $271(79.5 \%)$ had poor ventilation and $149(43.7 \%)$ were reported that they used indoor spray unsafely. However, $67.2 \%$ of them reported as they do not know how to apply indoor spray. As a result $66 \%$ of the respondents did not close food items during the spray and $73.3 \%$ of them close windows and doors during spray. The study found an indoor total suspended particulate matter (TSP) concentration $7881.6 \mu \mathrm{g} / \mathrm{m}^{3}$ during cooking. This was about 1.4 times when compared to non-cooking time. The study found statistically strong significant association with mother's education status 1.58 times more to develop respiratory health problems and also small kitchen size, kitchen ventilation, have strong significances 1.57 and 1.62 times respectively the occurrence of respiratory health problems. The Type of fuel for cooking, Time of spent on cooking and mothers' level of knowledge on effect of indoor air pollution also strong significances 1.71,1.80 and 2.0 times respectively association with respiratory health problems development.

Conclusion: Housing and kitchen characteristics, type of fuels and stoves are the main factors contributing to increased indoor air pollutant concentration and to increased prevalence of respiratory health problems.

Keywords: Household biomass fuel; Indoor spray; Indoor air Pollution; Respiratory health problems; AFI; factors contributing; exposures; Seka

DOI: $10.7176 / \mathrm{JMPB} / 61-03$

Publication date: November $30^{\text {th }} 2019$

\section{INTRODUCTION}

Energy is essential to human being sustaining basic need such as heating, lighting and cooking food. The source of energy varies depend on socio-economic factors. Most of the developed country use clear fuel from gas to electricity and solar energy. But almost all developing country population relies on biomass fuel in traditional ways for household energy [5].

Indoor air pollution is the major sources of health problems throughout the worldwide. The sources of indoor air pollution of worldwide include combustion of biomass fuel, coal, charcoal, wood [6, 26] furnishing, house construction material, volatile organic chemicals like cosmetics use in the homes and indoor insecticides spray [15, 20].The substantial emissions and accumulation of toxic pollutants, such as particulate matter, carbon monoxide, Sulphuroxide nitrous oxides, formaldehyde, and volatile organic compounds, within the household that affect the health of both those who are cooking and others in the surrounding area [5].

A majority of the Ethiopian population resides in areas where mosquito populations are endemic and high. As consequences, people use indoor residual spray in order to reduce the risk of infection and their annoying effects. In Ethiopia as elsewhere in developing countries indoor air pollution and the health problem related to indoor air pollution of biomass combustion [6] and noon combustion indoor spray is household predominate.

The great burden of these indoor air pollution problems falls largely on the areas where the majority of the population (95\%) traditionally lives and works in poor house condition [27, 28]. The pollution from the emission of biomass fuel is significant risk factors of respiratory health problems, which account the burden of worldwide associated with adult women and young children [5]. According to central statistic authority $95 \%$ of the household 
in Ethiopia experienced use of biomass fuel as the domestic energy [15, 27, 29].Ethiopia stands as the third largest traditional fuel user in the world, with the habit of burning fuel wood on traditional three stone open fires, which have high pollutions and a very low efficiency, compared to 70 to $80 \%$ for an electric stove [30].

Moreover, most areas of the country is endemic to diseases causing or annoying mosquitoes, thus households are expected to use natural or commercial indoor spray to avoid them. Both conditions are important to health problem risks especially on vulnerable groups of the population. This assessment is primary identify factors contribute on household biomass fuel use, housing condition; demographic factors, ventilation efficiency and indoor spray information through primary data collection on certain household level characteristics and indoor air pollution.

Both of the biomass energy use in traditional way and indoor spray in home are very important to health problem risks especially on vulnerable groups of adult women and young children spent most of their time near indoor effectively.

Seka town is one of the poor contracted town contain large population which have limitation of electric power live in very poor house condition. Use indoor kitchen type, use biomass fuel for cooking food, lighting and heating and the respiratory health problems are the major problems in the town. Due to the absence of pre-school most of young children spent their time near indoor and exposed to indoor air pollutants. It is one of the town which the respiratory problem seen in it. However, there exists a difference with their study findings the effect of environmental and behavioral factors of indoor air pollution has been addressed very limited to all parties of Ethiopia.

\section{LITERATURE REVIEW}

\section{Biomass combustion and indoor air pollution}

The combustion of biomass fuel in traditional stoves results to increased concentration of indoor air pollution. The concentration of indoor air pollution is affected by the different factors such as availability of fuel, environmental factors, housing conditions (e.g. size of rooms, number and size of windows, housing materials built from, and arrangement of rooms), socio economic factors, education status, and income of the household and type of stove, kitchen location and size, type fuel, ventilation efficiency and location of windows. Cooking in developing country always practice in limited efficiency of ventilation, young children and adult women who are cooking and present during cooking highly exposed from the emission of biomass fuel combustion [10, 13, 31].

The health problems of women and children in developing country of the indoor air pollution related to the biomass combustion $[10,32]$. The combination of the type of fuel source, kitchen, type of stoves and the behaviors of cooks and heats are determining the level of indoor air pollution. The type of housing structure is referees to ventilation efficiency, windows and doors air the major factors that to affect the level of pollutants from source.

\section{Association of indoor air pollution and biomass fuels}

Indoor pollution is the most health problems in the developing country which is associated with biomass fuel use for cooking and heating in traditional use of three stoves, open fire poorly ventilation absence of windows of kitchens are increases the impact of indoor pollutants shows strong association between biomass fuel combustion and increases acute respiratory health problems of adult women and young children. The indoor air pollution from the combustion of biomass fuel such as dung, crop residue, charcoal and wood are causal agent of the respiratory health problem in developing country. This association with biomass fuel as the primary source of domestic energy [13].

Almost 3 billion of the world's poorest people still depend on solid fuels (wood, animal dung, charcoal, crop wastes and coal) burned in inefficient and highly polluting stoves for cooking food and heating their homes resulting four million premature deaths of young children and adults women from acute respiratory health problems [3, 4].People cook with solid fuels at least once a day in around half of the world's households and the prevalence is even higher in rural areas of developing countries [33, 34].

A disproportionate number of these individuals reside in Asia and Africa: $95 \%$ of the population in Afghanistan uses these fuels, $95 \%$ in Chad, $87 \%$ in Ghana, $82 \%$ in India, $80 \%$ in China [8].Cooking in developing country always practice poor kitchen in traditional stoves in limited efficiency of ventilation, young children and adult women who are cooking and present during cooking highly exposed from the emission of biomass fuel combustion $[10,13]$.Indoor pollution is the major cause of respiratory health problems in the developing country due to traditional use of biomass energy for cooking and heating.

The health problems of women and children in developing country of the indoor air pollution related to the biomass combustion [10,32].Women are seriously at the risk of indoor air pollution exposure due to the longer time they spent in cooking food in the kitchen and young children affected by indoor air pollution due to they spend their time in kitchen with their mothers. Studies show strong association of biomass fuel combustion and acute respiratory infection among adult women and young children $[35,36]$ respiratory illness of the children in developing country living in household exposure to the biomass fuel have three times greater risk in developing 
to acute respiratory infection compared with those of household of developed country using cleaner fuel [37].

Individuals in developing country are typically exposed to indoor air at very high level of pollution between 3 to 7 hours in each day spent time in microenvironment on activity [38]. A recent study has characterized the exposure response relationship between biomass smoke exposure and acute respiratory health problems of children of rural Kenyan[35].Other studies reports which carry out South Africa, Uganda, Mozambique, and Ethiopia) shows the presence of high prevalence of ARI associated with the use of fire wood[25].In the developing country which is associated with biomass fuel use for cooking and heating in traditional use of three stoves, open fire poorly ventilation absence of windows of kitchens are increases emission of indoor pollutants are strong association with biomass fuel combustion and increases acute respiratory health problems of adult women and young children $[35,36]$.

\section{Health burden of household biomass fuel combustion}

Indoor air pollution resulting from the use of solid fuels is a significant public health concern in developing countries where a substantial proportion of the population relies exclusively on such fuels to meet the most basic energy needs. In these areas, it has been estimated that indoor air pollution resulting from the combustion of solid fuels may be one of the leading contributors to the global burden of disease, among environmental. WHO identifies indoor smoke from solid fuels among the top 10 health risks, and indoor air pollution is responsible for an estimated 2.7 percent of the global burden of disease and more than 1.5 million people premature death each year due to exposure to the smoke and other air pollutants from burning solid fuels.

Millions people suffer with difficulty in breathing, stinging eyes, and chronic respiratory disease. It is also estimated that acute respiratory infection (ARI) is one of the leading causes of child mortality in the world, accounting for up to $20 \%$ of fatalities among children under five, almost all of them in developing countries and indoor air pollution is thought to cause about one-third of ARI cases [39, 40].

This makes solid fuels the second most important environmental cause of disease after contaminated waterborne diseases and the fourth most important cause of overall excess mortality in developing countries after malnutrition, unsafe sex, and waterborne diseases [41]. In addition to impacts on mortality, IAP may have long lasting effects on general health and well-being: early exposure to IAP during childhood may stifle lung development, suggesting that the cost of this pollution may continue later in life.

Acute respiratory health problem in the developing country is the cause of the deaths. The exposure of indoor air pollution from the combustion of biomass fuel such as dung, crop residue, charcoal and wood has been a causal agent of the respiratory infection health problem in developing country. The relevant risk factors for the health impacts of exposure to indoor smoke from solid fuels include, at the most distal level, socioeconomic status, housing and ventilation, energy technology, and time-activity budgets, plus more proximal factors stove emissions, and finally the exposure and dose of the numerous pollutants or combinations of pollutants concentrations [22]. Air pollution from household fuel combustion is the most important global environmental health risk today. These new guidelines bring together the most recent evidence on fuel use, emission and human exposure levels, health risks, intervention impacts and policy considerations to provide practical recommendations to reduce this health burden [4].

\section{Determinants of exposure to indoor air pollutants}

Indoor air pollution sources that release pollutants into the air are the primary cause of indoor air quality problems in homes. Poor ventilation can increase indoor pollutant levels due to weak dilution of emissions from indoor sources and conditions that are not conducive for pollutant dispersal. There are numerous sources of indoor air pollution and these include domestic fuel sources such as coal, wood, paraffin, oil, tobacco products, asbestos products, pesticides used in the home, household cleaning products, etc [36].

The quality of the indoor air is thus depends on the housing conditions that allow and maintains the desired ventilation level. These conditions in turn determine the level of pollutants concentration emitted from different activities. For instances during biomass fuel burning the amount and characteristics of pollutants depend on many factors including types of biomass fuel, types of stoves, and types of kitchens, size of windows and biomass fuel and efficiency of ventilation. The original factors such as availability of fuel, environmental factors, accessibility of fuels, housing characteristics (e.g. size of house, member of windows, housing materials built from and arrangement of rooms) socio economic factors, education status and income [18].

The distance between the subject and fire source is unique identification for indoor air pollution which modified by who are involved in cooking and heating practices [18]. The combination of the type of fuel source, kitchen, type of stoves and the behaviors of cooks and heats are determining the level of indoor air pollution.

The type of housing structure is refers to ventilation efficiency, windows and doors air the major factors that to affect the level of pollutants from source. Education, income level and housing structures are important determinants that can affect the level of exposure during cooking and heating. Several household factors directly 
influence patterns of human exposure to cooking fuel smoke, which occurs both inside and around households using poor combustion. Fuel type, kitchen location, use and maintenance of stoves, household layout and ventilation, time-activity profiles of individual household members, and behavioral practices (such as where children are located when cooking is being done) have been shown to influence pollution levels and individual exposures [42].

Poorly vented combustion devices emitted toxic products of incomplete combustion. Further, the use of traditional stoves in small and poorly ventilated kitchens, in close proximity to household members on a daily basis, leads to exposures that are significantly detrimental to the health of family members, particularly to women and children, who spend the most time in or near the kitchen. Very young children are especially at risk, as they receive some of the highest exposures during vulnerable periods of growth [42, 43].

\section{Non-combustion indoor air pollution}

Volatile organic compounds are compound that have low boiling point and highly evaporate at room temperature to increases the concentration of indoor air pollution. Volatile organic pollutants are the major source of indoor pollution, are easily released in the indoor environment. Volatile organic compounds (VOCs) are important indoor air pollutants produced by evaporation at room temperature are from paints, wood, fabrics, cleaning agents, air fresheners, cosmetics, furnishings, pesticides, herbicides, insecticides are the major indoor air pollutants.VOC are the chemical pollutants emitted as gases from certain liquids [44].VOCs are the dominant sources pollutant contributing to the indoor air pollution concentrations and result in indoor levels up to 10 times higher than outdoors [44].

In some cases of the developing country pesticides and insecticides are the major indoor air pollution due to the misapplication and over use spray in home. Most of the time in developing country women and young children spend most of their time around home. Pesticides can take the form of a solid, liquid, powder or spray. The form will influence the way in which the pesticide can enter your body and potentially affect human health [45, 46].

Pesticides can enter the body through ingestion of food and water exposed to pesticides, when skin come into contact with pesticides directly or indirectly by touching pesticide-treated surfaces, through inhalation of pesticide vapors, sprays or dust and rub over eyes after handling pesticides [24]. Poisoning by exposure to pesticides may occur shortly after a single exposure (acute poisoning) or gradually after repeated exposures over a period of time( chronic poisoning [46].

A general feeling of excitement of acute poisoning from pesticides after exposure include: headache, dizziness, nausea, vomiting, stomach cramp, diarrhea, blurred vision, excessive eye watering, sweating and excess saliva [46, 47]. Short-term exposure to high concentrations of well-known pesticides, may result in headaches, dizziness, muscle twitching, weakness, tingling, excitement and nausea [48].Long-term exposure may cause liver and central nervous system effects, as well as increased cancer risk health problem [48].

\section{Indoor air pollution status in Ethiopia}

The indoor air pollution in households of Ethiopia is strictly limited to few quantitative attempts with indoor air pollution (IAP) measurements using small samples of households. About $99 \%$ of the Ethiopian rural population depends on biomass fuel as domestic source of household energy [29].

According to the Ethiopia central Statistical about $90 \%$ of the Ethiopian rural households are use the same room for cooking and living room as that used for daily activity. Over $90 \%$ of households in rural areas use a three stone traditional stove which is open stoves and poorly ventilated rooms and kitchens which can result in high emission of indoor air pollutants. The absence of sufficient ventilation in most of the households can be an essential constituent of increased risks of exposure to harmful pollutants [29, 49].

\section{METHODOLOGY}

\section{The study design and period}

The study design is cross-sectional, which employs an exposure assessment approach, collecting detailed primary data on several household-level exposure indicators (fuel type, stove type, kitchen type, housing type, ventilation, indoor spray etc.) and through the administration of a questionnaire. The quantitative data collection included monitoring level of total suspended particle matter in selected households during cooking and non cooking hours together with qualitative data. The study was conducted from May 1-30, 2017

\section{The Study area}

The study was conducted in Seka town which is located at $20 \mathrm{~km}$ from Jimma town and $372 \mathrm{~km}$ from the capital city of the country, Addis Ababa. The Woreda is represented by three agro-ecological zones namely Kola, Waynadega and Dega. The major source of income of the woreda is agriculture, mainly coffee and chat. The population of the town is composed of different ethnic groups where about $65 \%$ of the population is ethnic Oromo followed by Amhara and yam. The Seka town total population is 5212 males and 5966 females, a total of 11178 
people from 1620 households. The town has one health center and one hospital, three primary schools, one secondary and one vocational school. The town has an electrical energy access from the national grid; however, majority of the population uses biomass stoves for cooking as elsewhere in other towns. The town is among malaria areas in the zone.

\section{Population}

Source Population

The source population for this study was all women and caregivers living in SekaTown. However, including all household in the study is not possible due to financial and time constraints.

\section{Study population}

The study populations are all households with adult women/caregivers having children lesson five year and participate in cooking for the family. The study population was selected from all households by using random sampling based on the population size. Households without women and children lesson five year and sharing kitchen with other households were not included in the study. The study only considered one woman from each selected households.

\section{Sample size determination and selection techniques}

The sample size was determined based on population correction formula with $95 \%$ confidence interval, margin of error of 5\%. The proportion of population affected by indoor air pollution is not known for the study areas, thus a population proportion of $50 \%$ was considered for the selection of representative sample size. Finally, the number of study households was selected based on the kebeles' population proportion. Then, a systematic random sampling technique followed by lottery method was employed. According to information from the town administrative, the total population of the town is 1620 household. Therefore;

$\mathrm{n}=\frac{(\mathrm{Z} \alpha / 2)^{2} \mathrm{xp}(1-\mathrm{p})}{\mathrm{d}^{2}}$

$\mathrm{n}=\frac{(1.96)^{2}(0.5)(0.5)}{0.05^{2}}$

$\mathrm{n}=384$ households

Where

$\mathrm{n}=$ minimum sample size

$\mathrm{P}=$ the proportion of study population exposed for the risk factors $(50 \%)$

Zó $/ 2=$ Confidence interval $(95 \%)$

$\mathrm{d}=$ Margin of sampling error tolerated $(5 \%)$

Since the study population is $<10,000$, the population correction formula was considered.

$=\frac{n}{1+n / N}$

$=384 /(1+(384 / 1620))$

Thus, $\mathrm{n}=\mathbf{3 1 0}$ households plus $10 \%$ non-response rate, the final sample size was 341 households. Indoor air pollutant concentration measurements were made on about $10 \%$ of the households considered for the survey [50].

\section{Study variables}

Parameters considered for the study can be categorized into dependent and independent variables

\section{Dependent (outcome) variable}

- Prevalence of respiratory diseases

\section{Independent variables}

- Environmental factors: availability of fuels

- Housing factors: type and size of kitchen and number of window and ventilation systems

- Behavioral factors: time spent near kitchen and time of cooking food, keeping children in kitchen

- Socio-economic factors: income and educational status

- Demographic factors: age, sex, religious, ethnicity and residency of respondents

\section{Measurement of indoor air pollution concentration}

This study considered only the measurement of total suspended particulate matter (TSP) due to lack of fine particulate matter measuring equipment. As mentioned above, this study selected only $34(10 \%)$ of the surveyed 
households by taking into account different housing conditions [50]. The particulate matter measurement was made by placing the measuring device at different positions from the cooking areas. Accordingly, the measuring device was placed at $100 \mathrm{~cm}$ from the edge of cooking position, $100 \mathrm{~cm}$ from cooking sit position of women or child and from $150 \mathrm{~cm}$ away from door or window horizontally. The study considered sampling at both cooking and non-cooking time. The measurements also include kitchen size and observation of kitchen and door positions. The measurement also considered households approximately at a distance of 500 meter from the main road to control the effect of outdoor TSP on indoor TSP.

The concentration of the total particulate matter was calculated by subtracting initial weight of the device from the weight of the device after measurements from a certain volume, which expressed as;

$T S P=W \mathrm{f}-W \mathrm{i} / \mathrm{V}$

Where,

TSP $=$ Total suspended particulate matter

Volume air sample $(\mathrm{V})=$ air flow rate $\left(\mathrm{m}^{3} / \mathrm{min}\right) *$ sample run time $(\mathrm{min})$

$\mathrm{WI}=$ initial weight of clean filter $(\mu \mathrm{g})$

$\mathrm{Wf}=$ final weight of exposed filter $(\mu \mathrm{g})$

\section{Data collection and analysis}

Collection of the survey data was made by using open and close ended structured questionnaires. The questionnaires were used to guide the interview. Data on the prevalence of respiratory health problems was limited to one month occurrence of the problems before the date of data collection. This duration was chosen to avoid recall bias. The questionnaire was prepared in English and translated to local language Afan Oromo for better understanding and validation. A pilot-test was also performed on $5 \%$ of the population to avoid ambiguity of the questions. Additional data on housing conditions and structure was taken through observations. The survey data was collected by trained students from Health College and supervised by urban health extension workers. The measurement of indoor air pollution concentration was made by the principal investigator himself.

The survey data was analyzed by using statistical software package for social sciences version 20 (SPSS V.20). The association between outcome variables and co-varieties were made by using different regression models. The analysis on the concentration of indoor air pollutants were made by considering the average of the double measurements

\section{Quality assurance}

The quality of the data is essential for the validity of the analysis and robustness of the results. Therefore, to increase the quality of the data, first pre-test was performed on the questionnaires. Then, well qualified and trained data collectors were recruited and trained on the questionnaires along with their site supervisors. Trained supervisors were assigned to supervise data collectors, correct any encountered problems and check for its completeness and consistency at the end of each data collection day. Further data checking and editing was also performed prior to analysis.

\section{Discussions}

This study assessed factors contributing to indoor air pollutants exposure and related to prevalence of respiratory health problem among women and young children in Seka town. Indoor air pollution in developing country is to a large extent produced by household solid fuel use (SFU) for cooking and heating, usually involving open fires stoves with low combustion efficiency in poor ventilated environment [52]. Biomass fuel is the predominant fuel type in the study area where $100 \%$ of the respondents relying on biomass fuel for cooking and heating. Moreover, many of households $(59.5 \%)$ live in houses attached to the kitchen.

In addition, many of the houses contain small rooms with an average family size of more than five. About $80 \%$ of the households cook food around noon when most of the household members are at home. In addition, $77.4 \%$ of the households reported as they use kerosene for lighting. Thus, there is highly likely exposure to high amount indoor air pollutants emitted from the biomass and kerosene combustion [53]. Literature indicates that people using biomass energy for cooking exposed to high amount of indoor pollutants which can have adverse respiratory health problems [52]. Poor housing conditions, overcrowding and poor ventilation exacerbate the problems. Study made in Kenya shows the occurrences of a high prevalence of acute respiratory infections were observed in crowded households where large families inhabited in small living space and use biomass fuels especially during the cold season [54]. In current study about $90 \%$ of the houses have poor ventilation. Poorly ventilated houses are characterized by lack of chimneys and adequate windows to allow sufficient ventilation and removal of the smoke produced from combustion of biomass fuel. Such kinds of houses are known by high accumulation of soot and incomplete combustion byproducts. Literature shows that the location of kitchen, its ventilation and permeability of walls significantly affects exposure to indoor air pollutants of any kinds [55].

Studies have shown, indoor smoke in poorly ventilated houses can exceed acceptable levels for small particles 
in outdoor air by 100 fold [56]. This is evidenced in current study that the measured indoor air pollutant concentration from small size area of kitchen $(2 \mathrm{mx} 1 \mathrm{~m})$ is about two-folds compared to pollutant concentration measured in small size area kitchen (Table 6). The measured total mean concentration of suspended particulate matter released during cooking time in small size kitchen with mixed fuel was $13911.2050 \mu \mathrm{g} / \mathrm{m}^{3}$. The variation of the indoor air pollutant concentration with varying fuel might be due to homogeneity of the biomass for consistent and relatively efficient combustion process. There was also huge variation between cooking and non-cooking time. The measured total mean cooking time concentration of TSP $\left(7881.55 \mu \mathrm{g} / \mathrm{m}^{3}\right)$ was higher than the total mean concentration $\left(5574.57 \mu \mathrm{g} / \mathrm{m}^{3}\right)$ of non-cooking time with the same mixed fuel. It was agreed that with the energy ladder since mixed type fuel contains different higher polluting fuel like leaves, crop residues, twigs wood, charcoal, saw (sagatura) which have high potential to respiratory problems. Evidences show that incomplete combustion byproducts increases with decreasing kitchen size and ventilation [57]. As a result, the mean indoor air pollutant concentration measured during cooking time was $7881.55 \mu \mathrm{g} / \mathrm{m}^{3}$, which was about 1.4 times the

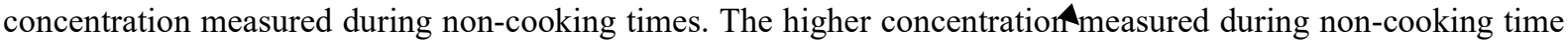
was due to low ventilation of the kitchen and dilution resulting to high residual pollutants.

The mean TSP concentration in this study was lower when compared to the study conducted in Addis Ababa showing a mean concentration of $50,000 \mu \mathrm{g} / \mathrm{m} 3$ [30]. However, the finding is comparable with the study finding from the rural India with a mean concentration of $4990 \mu \mathrm{g} / \mathrm{m} 3$ during cooking time [58] and rural area of Anilemo Woreda, Southern Ethiopia with a mean concentration of $6794.958 \mu \mathrm{g} / \mathrm{m} 3$ [5]. These measurements are made for short time during cooking time of $180 \mathrm{~min}$ and non-cooking time, thus, it is impossible to compare with the WHO air quality guideline (AQGs) value for 24 hours minimum indoor concentration of $50 \mu \mathrm{g} / \mathrm{m} 3$

Poor women and young children living in small and unventilated houses are highly vulnerable as shown in literature [12]. Particularly, particles with a diameters of below 10 microns, and particularly those less than 2.5 microns can penetrate deeply into the lung and appear to have the greatest potential for damaging health [59]. Although we are unable to measure particles with a diameter of less than 10 microns, the measured values might be sufficient to impose health problems.

Mothers are particularly vulnerable to the health effects of indoor air pollution as they spend a considerable amount of time in the kitchen cooking in traditional stoves. In this study $62.2 \%$ of the women responded as they spent more than three hours a day on cooking. That could be the reason why women are the second highest group in the family members next to children to develop respiratory health problems (Table 9). Exposure to noncombustion related indoor air pollutants should be equally stressed due to the fact that majority of the women do not have sufficient knowledge on the safety measures of these pollutants. About $67 \%$ of the women do not know the necessary safety measures of indoor chemical spray. As a consequence about $73 \%$ of the households spray chemicals closing windows and doors (Table 8).

Spraying pesticides in the home in closed door and window results in increased risks of the respiratory health problems among children in low-income household were the housing condition increases the probability of pest infestation and pesticide spray [60]. Children exposed to high concentrations of pollutants due to playing close to the floor, overuse ,misapplication and their higher resting metabolic rate and rate of oxygen consumption per unit body weight than adults, because they have a larger surface area per unit body weight to pest spray [61].

The Post-spray activity may cause exposure as well through improper behavior of beneficiaries regarding sprayed surfaces and cleanup and disposal of residue and any insects killed with the insecticides from the household after spraying [62] Infants and young children are the first in the family member to suffer from respiratory health problems due. Table 7 shows the prevalence of the respiratory health problems among households. It is shows that $24.3 \%$ of the respondents reported as some of their family members suffered from the respiratory health problems. Children account for $43.1 \%$ of the family members affected by respiratory health problems in the past one month period followed by women $(32.5 \%)$. The high number of prevalence of the respiratory health problems can be associated to any kind of indoor air pollution exposure [63]. The respiratory health problem is among the leading cause of death in low income household where more than half of the respiratory health problems occur among young children and adult women. Most of these deaths could be associated to exposure to high indoor air pollutants.

\section{REFERENCES}

1. Masera O R, D.R., Berrueta V., From cook stoves to cooking systems. the integrated program on sustainable household energy use in Mexico, 2005( Energy Sust).

2. Zhang, M.A.H.M.S.S.W.Y.Z.D., Urban and rural exposure to indoor air pollution from domestic biomass and coal burning across China. H.E.S. Mestl et al. / Science of the Total Environment, 2007(377): p. 12-26.

3. Mittal, R.K.N.G.N.G.K.S.S.N.a.J., Indoor Air Pollution and Respiratory Illness in Children from Rural India. Chest Diseases \& Allied Sciences, 2014.(Indoor Pollution and Respiratory Illness).

4. WHO, household fuel combustion. 2014.

5. Tadesse, R., household biomass fuel use and acute respiratoryinfections among younger children. 2015. 
6. Nimesh Patel, B.O., Swastika Narayan, Manthan Sheth, Indoor Air Pollution from Burning Biomass \& ChildHealth. International Journal of Science and Research (IJSR), India Online ISSN, 2013.

7. WHO, Air quality guidelinesfor particulate matter, ozone, nitrogendioxide and sulfur dioxide. 2006.

8. Duflo, E., M. Greenstone, and R. Hanna, Indoor air pollution, health and economic well-being. SAPI EN. S. Surveys and Perspectives Integrating Environment and Society, 2008(1.1).

9. Soo-jeong Lee, P.M., Brienne Diebolt-Brown, Michelle J. Lackovic Louise N. Mehler Johnbeckman justin Waltz joanne B. Prado Yvette A. Mitchell Sheila A. Higgins Abby Schwartzand Geoffrey M. Calvert, Acute illnesses associated with exposure to fipronil surveillancedata from 11 states in the United States. 2010. (Clinical Toxicology): p. 737-744.

10. Birnbaum, L., Assessing Exposures and Health Effects Related to Indoor Biomass Fuel Burning. 2015(National Institutes of HealthU.S).

11. Kalpana Balakrishnan, P.R., Sankar Sambandam1, Gurusamy Thangavel, Santu Ghosh, Priscilla Johnson, Krishnendu Mukhopadhyay, Vidhya Venugopal1 and Vijayalakshmi Thanasekaraan, Air pollution from household solid fuel combustion in India: an overview of exposure and health related information to inform health research priorities. Global Health Action, 2011.

12. (NHRC, Situation Analysis of Indoor Air Pollution and Developmentof Guidelines for Indoor Air Quality Assessment and HouseBuilding for Health. 2004.

13. Ezzati, M., Energy technology, indoor air pollution, and respiratoryinfections in developing countries. 2000(Household Energy in Developing Countries).

14. Smith, M.A.D.M.K.R., Assessing the environmental burden of diseaseat national and local levels. Indoor smoke from solid fuels, 2004(Estimates of relative risk ).

15. Qasim, A.B., Malik Muhammad Anees,Muhammad Usman Ghani, Moeen Khalid, Jahanzaib Malik, Adila Kokab, Health Risk Assessment of Indoor Air Quality in Developing Countries. 2014.

16. Kirk S Weber, A.H., Alisa Jenny, Lisa M Thompson, John Balmes, Anaité Diaz, Byron Arana, Nigel Bruce, Eff ect of reduction in household air pollution on childhoodpneumonia in Guatemala. 2011.p. 1682.

17. Bruce, N., R. Perez-Padilla, and R. Albalak, Indoor Air Pollution in Developing Countries: A Major Environmental and Public Health Challenge. 2000(Bulletin of the World Health Organization

18. Kammen, E.M.a., evaluating the health benefits of transitions in household energy technologies in Kenya. 2002(Energy Policy).

19. Francisco, P., combustion of solid fuels and indoorair quality in primarily developingcountries. 2016.

20. WHO, generic risk assessment modelfor indoor residual sprayingof insecticides. 2011.

21. Nancy K. Wilson, W.J.S., Nicole Iroz-Elardo and Jane C. Chuang, Exposures of preschool children to chlorpyrifos, diazinon,pentachlorophenol, and 2,4-dichlorophenoxyacetic acid over 3 years from2003 to 200. Journal of Exposure Science and Environmental Epidemiology, 2010: p. 546-558.

22. Marion, H., Marzia, Simoni", Giovanni Viegi and Isabella Annesi Maesano, Respiratory health and indoor air pollutantsbased on quantitative exposureassessments. 2012.(air pollution and lung disease).

23. Marsha K. Morgan, Linda S. Sheldon, Carry W. Croghan, Paul A. Jonesa,Jane Chuang, Nancy K. Wilson, An observational study of preschool children at their homes anddaycare centers in Ohio. 2007.

24. Eleftherohorinos, C.A.D.a.I.G., Pesticide Exposure, Safety Issues, and Risk Assessment Indicators. International Journal ofEnvironmental Research and Public Hea, 2011: p. 1402-1419.

25. Zheng Zhoua, K.D., Raphael . Arkub, Audrey Quayec, Allison . Hughesd, Jose Vallarinob,John . Spenglerb, Allan Hilla, Samuel Agyei-Mensahc and Majid Ezzat, Household and community poverty, biomassuse, and air pollution in Accra, Ghana. 2011. p. 11028-11033.

26. Yinlong Jina, X.M., Xining Chenb, Yibin Chenga, Enis Barisc, Majid Ezzatid,for the China Rural Energy and Health Research Group, Exposure to indoor air pollution from household energyuse in rural China: The interactions of technology, behavior,and knowledge in health risk management. 2006: p. 3161-3176.

27. Desalegn, B., Household fuel use and acute respiratory infections among younger children: an exposure assessment in Shebedino Wereda, Southern Ethiopia. 2011.(African Journal of Health Sciences ).

28. Shahpar, S.M.a.C., The health benefits of interventions to reduceindoor air pollution from solid fuel use:a cost-effectiveness analysis. 2004

29. Central Statistical, A.C., Ethiopia, Statistical Abstract Addis Ababa Ethiopia. 2007.

30. Jargstorf, B., Renewable Energy \& Development, Deutsche Gesellschaft Technische Ethiopian Rural Energy Development and Promotion Centre,Addis Ababa, Ethiopia. 2004.

31. Iswori Lal Shrestha, S.B.K., Salil Devkota,Sunil Kumar Joshi,Srijan Lal Shrestha, Situation Analysis of Indoor Air Pollution and Developmentof Guidelines for Indoor Air Quality Assessment and House Building for Health. 2004.

32. Nimesh Patel, B.O., Swastika Narayan, Manthan Sheth, Indoor Air Pollution from Burning Biomass \& ChildHealth. 2013.

33. Smith, K.R., S. Mehta, and M. Maeusezahl-Feuz, Indoor air pollution from household use of solid fuels. 
Comparative quantification of health risks: global and regional burden of disease attributable to selected major risk factors, 2004. : p. 35-93.

34. Mehta, S. and C. Shahpar, The health benefits of interventions to reduce indoor air pollution from solid fuel use: a cost-effectiveness analysis. Energy for sustainable development, 2004. p. 53-59.

35. SMITH, K.B.S.S.P.R.S.M.A.K.R., Exposure assessment for respirable particulates associated with household fuel use in rural districts of Andhra Pradesh India. Exposure Analysis and Environmental Epidemiology 2004.

36. Daisey, A.M.G.A., Indoor air quality, ventilation and health symptoms in schools an analysis of existing information. 2003(Indoor air quality, ventilation and health symptoms in schools): p. 53-64.

37. Gordon, D.F.N.B.S., Indoor air pollution from biomass fuelsmoke is a major health concern in the developing world. 2008(Indoor air pollution from biomass fuel smoke is a major health concern in the developing world): p. $843-851$.

38. WHO, he health effects of indoor air pollution exposure indeveloping countries. 2002.

39. WHO, The world health report: reducing risks, promoting healthy life. 2002: World Health Organization.

40. WHO, Innovative Approaches in Assessing Children's Exposure to Pesticides. Northwest Bulletin, 2006. 21(Family and Child Health).

41. Bruce, N., et al., eds. "Indoor Air Pollution," In Disease Control Priorities in Developing Countries. $2^{\text {nd }}$ Edition, Jamison, D.T., et al, Eds. 2006, Oxford University Press: Washington D.C: World Bank, New York.

42. Smith, K.R., et al., Energy and human health. Annual Review of public health, 2013. p. 159-188.

43. Kammen, M.E.a.D.M., The Health Impacts of Exposure to Indoor Air Pollution from Solid Fuels in Developing Countries: Knowledge, Gaps,and Data Needs. Discussion Paper, 2002

44. Myatt, T., Volatile Organic Compounds in the Home. Health Implications, and Solutions, 2015.

45. Tursk, T.N.M.W.W.Z.W.A., content of transfluthrin in indoor air during the use of electro-vaporizers. Content of transfluthrin in indoor air during the use of electro-vaporizers, 2011(Transfluthrin in indoor air): p. 85-88.

46. Inc, P.C.A., Madagascar supplemental environmental assessmentfor indoor residualspraying for malariacontrol. Indoor Residual Spraying, 2013.

47. Peter Ashley, M.N., Maureen A. Wooton,Jennifer Zewatsky,Joanna Gaitens,Jack Anderson, Healthy Homes Issues:Pesticides in the Home Use,Hazards, and Integrated Pest Management. 2006. 3(Pesticides in the Home).

48. Garry, V.F., Pesticides and children. Toxicology and Applied Pharmacology 2004: p. 152-163.

49. Worku Tefera, A.A., Frank Gilliland, Alemayehu Worku, Mehari Wondimagegn, Abera Kumie,Jonathan Samet, Kiros Berhane, Indoor and Outdoor Air Pollution- related Health Problem in Ethiopia: Review of Related Literature. 2016(The health burden related to indoor and outdoor air pollution in Ethiopia ).

50. S.Lemeshow, L.a., A practical manual of sample size determination in healthstudies. World Health Organization, Geneva, 1991.

51. Bukalasa, J.S., Indoor Air Pollution, Social Inequality and Acute RespiratoryDiseases in Children in Tanzania. 2011.

52. Larsen, B., Copenhagen Consensus Challenge Paper Air Pollution. 2008.

53. WHO, Burning Opportunity: Clean Household Energy for Health, Sustainable Development, and Wellbeing of Women and Children 2016.

54. Fund, U.N.C.s., A Situation Analysis for Children and Women in Kenya. Nairobi. 1998.

55. Kalpana Balakrishnan, S.M., Priti Kumar,Padmavathi Ramaswamy,Sankar Sambandam,Kannappa Satish Kumar,Kirk R. Smith, Indoor Air PollutionAssociated withHousehold Fuel Use in India. 2004(An exposure assessment and modeling exercise in rural districts of Andhra Pradesh, India).

56. WHO, Indoor Air Pollution and Health. Fact Sheet. 2005.(Children's Health and the Environment.A Global Perspective.A Resource Guide for the Health Sector).

57. WHO, G., Indoor air pollution and respiratory tract infections in children. 2007.

58. N.Goel, N.G., K.Singh, S.Nagar and J.Mittal,R.Kumar, Indoor Air pollution andrespiratory Illness in children from Rural India. The Indian Journal of chest Disease\&Allied sciences. 2014. Vol 56: p.:80-81.

59. Wickramasinghe.A, Gendered Sights and Healthy Issues in the Paradigm of Bio-Fuel in SriLanka. 2001. 4(energianews): p. 12-14.

60. Peter Ashley, M.M.A.W., Jennifer ZewatskJoanna Gaitens,Jack Anderson, Pesticides in the Home Use,Hazards, and Integrated Pest Managemen. 2006(Pesticides in the Home).

61. Mauskar, J.M., ambient air quality,respiratory symptoms and lung function of children in delhi. 2008.

62. anderson, s., indoor residual sprayingsupplemental environmentalassessment. 2013.

63. Moya, J., Bearer, C. \&Etzel, R. , Children's Behavior and Physiology and How It Affects Exposure to Environmental Contaminants. 2004(Pediatrics): p. 113, 996. 


\section{DECLARATION}

\section{Ethics approval and consent to participate}

The study was conducted after getting approval from the institute's Ethical Review Board.. Participants were insured confidentiality and anonymity throughout the data collection and analysis. Moreover, participation in the study was based on informed consent and participants can decline at any stage of the data collection process. Permission to conduct the study will be sought in writing from the local authorities. Prior to the interview, all voluntary participants were presented with the aim of the study and how the collected information will be used. They were informed about the confidential treatment of their data and were asked to sign informed consent forms before participation.

\section{Consent for publication}

Not Applicable.

\section{Availability of data and materials}

The datasets used and/or analyzed during the current study are available from the corresponding author on reasonable request.

\section{Competing of interests}

The authors declare that they have no competing interests regarding the publication of this article.

\section{Funding}

The study was funded by Jimma University.

Authors' contributions

BT analyzed and interpreted the data. CK and SF reviewed the interpretation and analysis, and contributed in writing the manuscript. All authors read and approved the final manuscript.

Acknowledgement

We are grateful for Jimma University for funding our research project. We also thank study participants for their good will and cooperation. 